\title{
Дефицит $\alpha_{1}$-антитрипсина в практике пульмонолога
}

\author{
0.Г.Соловьева ${ }^{1,2}$ \\ 1 - ГБОУ ВПО "Тюменская государственная медицинская академия" Минздрава России: 625030, Тюмень, ул. Одесская, 54; \\ 2 - Консультативно-диагностическая поликлиника им. Е.М.Нигинского: 625027, Тюмень, ул. Мельникайте, 89а
}

\section{Резюме}

Дефицит $\alpha_{1}$-антитрипсина (ААТ) - одно из редких заболеваний респираторной системы. Генетические факторы риска возникновения ХОБЛ являются причиной дефицита ААТ с развитием первичной эмфиземы легких. Ключевая роль в подтверждении диагноза принадлежит генотипированию ААТ. Раннее выявление дефицитных фенотипов ААТ необходимо для разработки программы профилактики и лечения хронической обструктивной болезни легких с целью замедления прогрессирования эмфизематозных изменений в легких. Представлен клинический случай наследственной недостаточности AAT у пациента с дефицитным фенотипом PiZZ. Предложен алгоритм диагностики заболевания.

Ключевые слова: дефицит $\alpha_{1}$-антитрипсина, генотипирование, первичная эмфизема легких.

DOI: 10.18093/0869-0189-2015-25-4-505-508

\section{$\alpha_{1}$-Antitripsin deficiency in a pulmonologist' practice}

\section{G.Solov'eva ${ }^{1,2}$}

1 - E.M.Niginskiy Tyumen' State Medical Academy, Healthcare Ministry of Russia: 54, Odesskaya str., Tyumen', 625030, Russia;

2 - E.M.Niginskiy Reference Outpatient Clinic: 89A, Mel'nikayte str., Tyumen', 625027, Russia

\section{Summary}

$\alpha_{1}$-Antitripsin deficiency (AAT) is an orphan respiratory disease. Genetic risk factors of chronic obstructive pulmonary disease (COPD) can cause AAT and primary emphysema of the lungs. AAT genotyping plays the key role for diagnosis. Early detection of AAT deficient phenotypes is crucial for prevention and treatment of COPD and slowing emphysema progression. A case of inherited AAT deficiency in a patient with deficient phenotype PiZZ is described in this article. A diagnostic algorithm for AAT is proposed.

Key words: alfa1-antitripsin deficiency, genotyping, primary emphysema.

По данным Всемирной организации здравоохранения (ВО3) хроническая обструктивная болезнь легких (ХОБЛ) занимает 4-е место среди всех причин смерти населения в мире после ишемической болезни сердца, инсульта и респираторных инфекций. Согласно GOLD (Global Initiative for Chronic Obstructive Lung Disease - Глобальная инициатива по ХОБЛ, 2014) к наиболее распространенным и широко изучаемым внешним факторам риска возникновения ХОБЛ относятся длительное ингаляционное воздействие сигаретного дыма, профессиональные вредности, промышленные поллютанты, суровые геоклиматические условия, приводящие к хроническому воспалению в стенках воздухоносных путей и развитию эмфиземы легких. Однако в последние 30 лет особый интерес вызывают генетические причины возникновения ХОБЛ, протекающей с тяжелым бронхообструктивным синдромом и дыхательной недостаточностью [1]. При сочетании внешних неблагоприятных факторов с табакокурением первые признаки заболевания могут появиться в возрасте 30-40 лет, при отсутствии табакокурения в 50-60 лет [2]. Понимание роли наследственной предрасположенности к респираторным заболеваниям в сочетании с анамнестическими данными имеет большое значение для ранней диагностики, профилактики и в выборе тактики лечебных мероприятий. Ярким примером генетической предрасположенности к ХОБЛ является дефицит $\alpha_{1}$-анти- трипсина (ААТ) с аутосомно-рецессивным типом наследования, встречающийся относительно редко (1,0-4,5 \% случаев от общего числа больных), клинически проявляющийся первичной эмфиземой легких (семейная форма эмфиземы) [3], циррозом печени [4], реже - панникулитом [5]. ААТ представляет собой гликопротеид молекулярной массой 52 кДА, относится к семейству сериновых протеаз серпинам, синтезируется в гепатоцитах, в меньшей степени - в моноцитах, легочном и кишечном эпителии [6]. Высвобождаясь в кровь, ААТ инактивирует протеолитические ферменты лейкоцитов, главным образом эластазу нейтрофилов, обеспечивая защиту альвеол и эластического каркаса межальвеолярного интерстиция легких от повреждения [7]. Нормальное содержание ААТ в сыворотке крови составляет 0,9-2,0 г / л. Дефицитом ААТ считается уровень в сыворотке крови ниже 0,8 г / л (80 мг / дл). Ген ATT - Pi, картированный на правом плече 14-й хромосомы, содержит 5 экзонов. Экзон 5 - область частых мутаций, связанных с ААТ-недостаточностью. Нормальными аллелями гена $\mathrm{Pi}$, преобладающими у большинства людей, являются М-аллели (номенклатура аллелей основана на электрофоретической подвижности в крахмальном геле). Среди дефицитных аллелей чаще встречаются PiZ и PiS [8, 9]. Z-аллель характеризуется заменой нуклеотида глутамата на лизин в позиции 342, a S-аллель заменой глутамата на валин в позиции 264. Предположительно 1-4 \% 
всего населения являются носителями PiZ-аллелей. У обладателей фенотипа Pi(null) AAT не вырабатывается вовсе. Для гомозигот PiZZ характерна экспрессия АAТ, составляющая 10-15\% от нормального уровня (10-40 мг / дл), для PiSS и гетерозигот MZ, MS и SZ она составляет 20-60 \% (45-120 мг / дл) [10]. Тяжелый по прогнозу вариант PiZZ неравномерно распределен в различных популяциях. Он встречается с частотой до $1: 6000$ человек [11] и характеризуется панлобулярной эмфиземой легких. Учитывая инвалидизацию в молодом возрасте пациентов с ХОБЛ на фоне наследственного дефицита ААТ, ранняя диагностика с выявлением количественного уровня ААТ имеет большое значение [12]. По рекомендациям экспертов ВОЗ (Женева, 1996) в Европе, США, Канаде и других развитых странах сформированы национальные регистры с показателями уровня ААТ населения. В Российской Федерации имеются лишь немногочисленные генетические исследования дефицита ААТ, свидетельствующие о низкой диагностике этого заболевания среди жителей России. Наиболее вероятной причиной является ограниченность знаний докторов о редком генетически-ассоциированном заболевании респираторной системы и отсутствие представления об алгоритме диагностики в случае подозрения на него. Большинство медицинских лабораторий России не включают определение уровня и генотипирование ААТ в перечень исследований.

Целесообразность проведения скрининга дефицита с последующим генотипированием ААТ обусловливает необходимость выявления групп риска среди пациентов с первичной эмфиземой легких [13].

В табл. 1 представлены показания для исследования уровня АAТ.

В случае подозрения на дефицит ААТ при наличии одного или нескольких из перечисленных критериев предлагается алгоритм диагностики (см. рис. 1).

Лечение дефицита ААТ включает легочную реабилитацию (беседы о прекращении курения, ограничение пребывания в местах, содержащих аэрополлютанты, профилактика сезонных вирусных заболеваний, тренировка дыхательной мускулатуры, проведение

Таблица 1

Критерии определения $A A T$

Table 1

Diagnostic criteria for $\alpha_{1}$-antitripsin deficiency

ХОБЛ среди пациентов молодого возраста (курящие и некурящие)
Раннее появление эмфиземы легких
Бронхоэктатическая болезнь
Бронхиальная астма, трудно отвечающая на лечение
Частые обострения бронхита, пневмонии
Быстрое прогрессивное снижение ФВД
Хронический кашель и одышка
Семейный анамнез заболеваний легких и печени
Заболевание печени неясного генеза
Наследственный дефицит ААТ
Панникулит / васкулит

Примечание: ФВД - функция внешнего дыхания.

Пациент с показаниями для исследования уровня ААТ

\section{r}

Определение количественного содержания ААТ в сыворотке крови

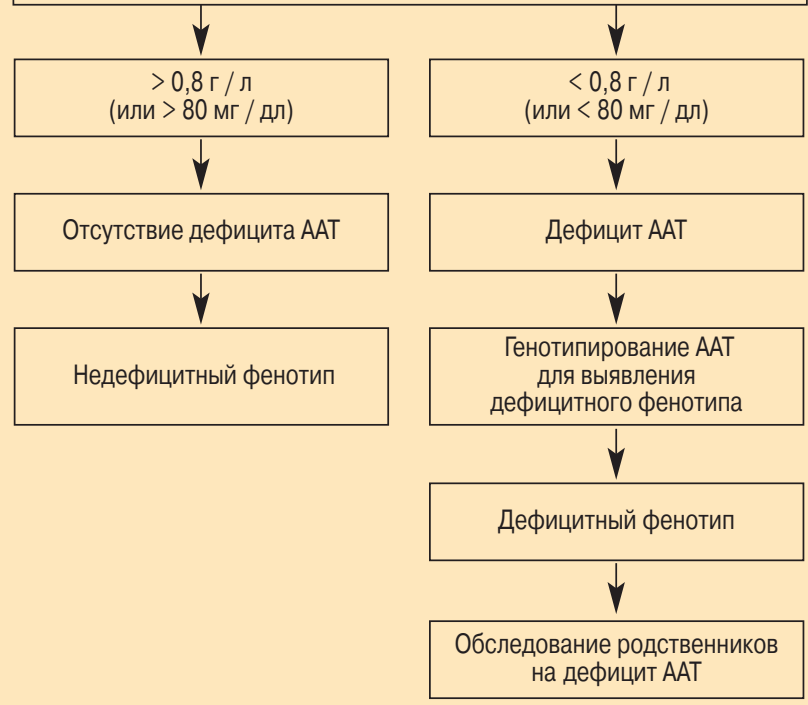

Рис. 1. Алгоритм диагностики дефицита AAT

Figure 1. A diagnostic algorithm for $\alpha_{1}$-antitripsin deficiency

вакцинации против гриппа и пневмонии, соблюдение диеты), адекватную базисную терапию и эффективное лечение обострений ХОБЛ. Основным лечебным мероприятием, направленным на замедление прогрессирования эмфизематозных изменений, является длительная заместительная терапия человеческим AАТ, направленная на поддержание постоянной защитной концентрации ААТ > 0,8 г / л [14].

Приводится описание клинического случая тяжелого дефицита ААТ.

Пациент К.М. 1951 года рождения, сельский житель (Тюменская обл.), обратился к пульмонологу в июне 2014 г. с жалобами на одышку, усиливающуюся при небольшой физической нагрузке, ходьбе, одевании и раздевании, поднятии тяжестей, наклонах, колке дров. Одышка с непереносимостью физических нагрузок беспокоит $\approx 5$ лет, в последние 2 года усилилась.

Из анамнеза. Стаж курения 1 год: периодически в 1972 г., в дальнейшем никогда не курил. Со слов матери, в детстве пациент был очень ослаблен, трудно ходил, тело - с большим животом, тонкими ручками и ножками. Отец пациента (некурящий) умер от одышки, не дожив до пожилого возраста. По образованию - инженер, трудовой стаж с 21 года; несколько лет работал комбайнером, затем в кабинете с бумагами (проводил проверку сельхозтехники в совхозе), был в контакте с бензином, соляркой. Профессиональные вредности отрицает. С 1972 по 1975 г. занимался легкой атлетикой (бег). Живет в частном благоустроенном доме. В 1996 и 2001 гг. перенес тяжелую двустороннюю пневмонию, после чего появился периодический кашель с мокротой, одышка при физической нагрузке, ежегодные обострения бронхита, в последние 3 года - с частотой 2-3 раза в год. В качестве базисной терапии использует Формотерол и Беклометазон. В 2000 г. был прооперирован по поводу стеноза позвоночного канала поясничного отдела, в 2010 г. - удаление паховой грыжи. Описторхоз с 2001 г. (дегельминтизация не проводилась), гастроэзофагеальная рефлюксная болезнь, хронический гастрит. Наличие туберкулеза, гепатита и аллергии отрицает. При контакте с триггерами (домашняя и библиотечная пыль, сигаретный дым, шерсть животных, пыльца растений) гиперреактивность бронхов не отмечается. Объективно. Пациент удовлетворительного питания, масса тела 88 кг, рост - 176 см (индекс массы тела $-28,4$ кг / м²). Грудная 


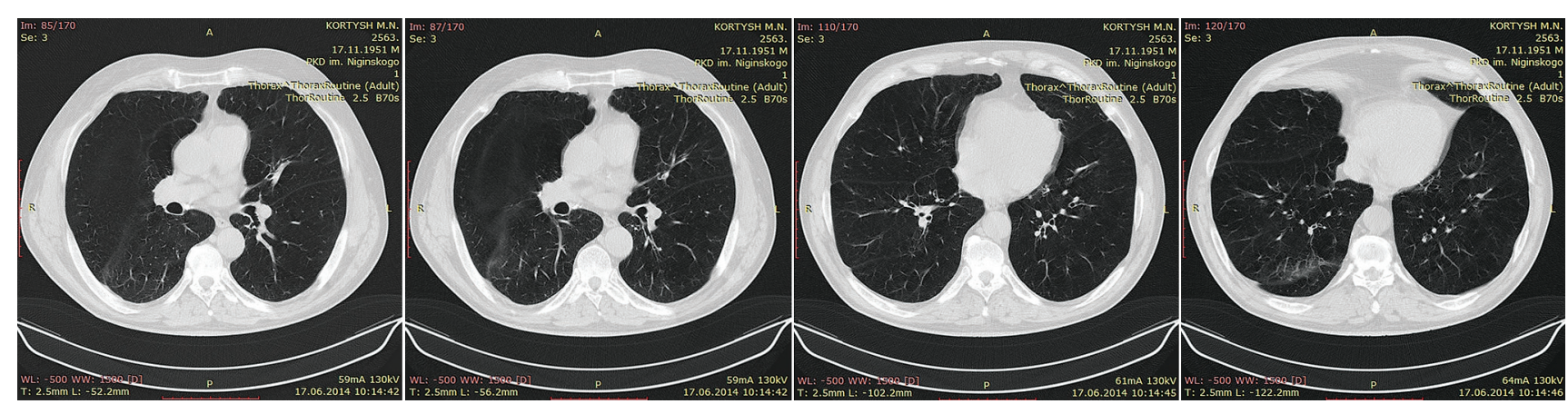

Рис. 2. Панлобулярная эмфизема легких у пациента с тяжелым дефицитом AAT

Figure 2. Panlobular emphysema in a patient with severe $\alpha_{1}$-antitripsin deficiency

ФВД у пациента с тяжелым дефицитом ААТ в 2014 и 2003 ге.

Table 2

Lung function in 2014 and 2003 in a patient with severe $\alpha_{1}$-antitripsin deficiency

\begin{tabular}{|c|c|c|c|c|c|c|}
\hline Год & $0 \Phi B_{1}, \%$ & ФЖЕЛ, \% & ОФВ ${ }_{1}$ / ФЖЕЛ & $\mathrm{MOC}_{75}, \%$ & MOC $_{50}, \%$ & MOC $_{25}, \%$ \\
\hline 2014 & 45,1 & 61,0 & 58,1 & 29,9 & 20,1 & 28,3 \\
\hline 2003 & 90,0 & 83,0 & 108,4 & 97,0 & 70,0 & 93,0 \\
\hline
\end{tabular}

Примечание: ОФВ 1 - объем форсированного выдоха за 1-ю секунду; ФЖЕЛ - форсированная жизненная емкость легких; ОФВ 1 / ФЖЕЛ - индекс Генслера; МОС $25-75$ - максимальная объемная скорость на уровне $25-75 \%$ ФЖЕЛ.

клетка эмфизематозной формы, небольшой акроцианоз. Перкуторно: легочный звук с коробочным оттенком по всем полям, над легкими дыхание жесткое, единичные сухие хрипы, частота дыхательных движений - 16 в минуту. Тоны сердца приглушены, ритмичные, частота сердечных сокращений - 70 в минуту. Артериальное давление - 120 / 80 мм рт. ст. Живот мягкий, безболезненный. Границы печени увеличены до 3 см от края реберной дуги. Периферических отеков нет. При проведении 6-минутного шагового теста сатурация в покое до теста составляла 94 \%, после ходьбы (448 м) - 88-89\%.

Лабораторные исследования. Показатели общего анализа крови в пределах нормы. Биохимическое исследование крови: общий белок - 66 г / л, креатинин - 80,5 мкмоль / л, общий билирубин 20,0 ммоль / л, аланинаминотрансфераза - 28 ЕД, аспартатаминотрансфераза - 22 ЕД, глюкоза крови - 5,5 ммоль / л, холестерин - 4,23 ммоль / л, общий $\mathrm{IgE}-249 \mathrm{ME} /$ мл (норма - до $100 \mathrm{ME} /$ мл). Hbs-Ag, HCV и ВИЧ - отрицательные.

Концентрация одного из показателей антиэластазной активности $\alpha_{2}$-макроглобулина в сыворотке крови соответствовала верхней границе нормы - 2,49 г / л (референсные значения - 1,19-2,54), что расценивается как предельно компенсаторная реакция.

По данным электрокардиограммы от 12.05 .14 - ритм синусовый, 60 в минуту, диффузные изменения в миокарде. По результатам компьютерной томографии легких от 17.06.14 выявлены выраженная панлобулярная эмфизема по всем легочным полям, уплотнение участков сохранившейся паренхимы по типу матового стекла без очаговых и инфильтративных изменений с обедненным легочным рисунком, кальцинаты в правом корне и стенках крупных несколько деформированных бронхов, в нижних отделах легких фиброзные тяжи (рис. 2).

При эхокардиографическом исследовании от 18.06.14 выявлены удовлетворительная сократительная способность миокарда левого желудочка (фракция выброса - 66 \%), незначительная гипертрофия межжелудочковой перегородки (12 мм), нормальное систолическое давление в легочной артерии (19 мм рт. ст.).

По данным спирометрического исследования от 17.06.14 (аппарат Spiro Pro BTL-08) обнаружены выраженные нарушения бронхиальной проводимости на уровне мелких, средних и крупных бронхов при умеренно сниженной ФЖЕЛ (табл. 2), проба с беродуалом положительная (прирост ОФВ 1 - 16,6 \%). В 2003 г. показатели ФВД соответствовали норме.

С учетом семейного анамнеза одышки, отсутствия курения, данных проводимого обследования, возникло подозрение на наличие у пациента дефицита ААТ. Анализ крови от 17.06.14 показал 4-кратное снижение уровня ААТ от нижней границы нормы 0,2 г / л. Полученный результат был подтвержден медико-биоло- гической лабораторией НИИ "Медицины труда" (Москва) и соответствовал 0,29 г / л. При генотипировании ААТ определен фенотип PiZZ.

На основании полученных данных был поставлен клинический диагноз: наследственный дефицит АAT (фенотип PiZZ). Первичная эмфизема легких. ХОБЛ тяжелой стадии, осложненная хронической дыхательной недостаточностью I степени. Посттуберкулезные изменения легких в виде кальцинатов.

Пациенту разъяснена необходимость профилактики простудных заболеваний, тренировки дыхательной мускулатуры, соблюдения диеты, ограничения воздействия аэрополлютантов в местах пребывания. Проведена вакцинация антипневмококковой вакциной "Пневмо-23". Рекомендовано базисное лечение ХОБЛ с включением длительно действующих $\beta_{2}$-агонистов (Индакатерол 150 мкг в сутки) и М-холинолитиков (Гликопирроний 50 мкг В сутки). В качестве специфического метода лечения дефицита AАТ рекомендована заместительная терапия препаратом AАT, полученного из человеческой очищенной донорской плазмы, из расчета 60 мг / кг массы тела внутривенно еженедельно.

У дочери пациента - К. 35 лет (некурящая) - также выявлен дефицит АAT - 0,79 г / л, определен фенотип PiMZ при отсутствии клинической картины ХОБЛ и эмфизематозных изменений в легких по данным компьютерной томографии. Пациентке рекомендованы соблюдение профилактических мер, ежегодный контроль показателей спирограммы [15] и компьютерной томографии органов грудной полости.

\section{Заключение}

Таким образом, ранняя диагностика дефицита и генотипирование ААТ направлены на замедление прогрессирования и развития осложнений ХОБЛ. Помимо количественного определения ААТ исследование фенотипа родственников пациента позволяет разработать индивидуальную программу профилактики и лечения до манифестации заболевания, чтобы отсрочить начало появления деструктивных процессов в респираторной системе.

\section{Литература}

1. Аверьянов А.В., Поливанова А.Э. Дефицит $\alpha_{1}$-антитрипсина и хроническая обструктивная болезнь. Пульмонология. 2007; 3: 103-109. 
2. Strange C., Stoller J.K., Sandhaus R.A. et al. Results of a survey of patients with alpha1-antitrypsin deficiency. Respiration. 2006; 73: 185-190.

3. Бродская О.Н. Наследственная недостаточность $\alpha_{1}$-антитрипсина. Атмосфера. Пульмонология и аллергология 2008; 4: 58-59.

4. Dawwas M.F., Davies S.E., Griffiths W.J. et al. Prevalence and risk factors for liver involvement in individuals with PiZZ-related lung disease. Am. J. Respir. Crit. Care Med. 2013; 187 (5): 502-508.

5. Олисова О.Ю., Грабовская О.В., Теплюк Н.П. и др. Панникулит, обусловленный дефицитом $\alpha_{1}$-антитрипсина. Российский журнал кожных и венерических болезней. 2014; 3: 32-35.

6. Pini L., Tiberio L., Venkatestan N. et al. The role of bronchial epithelial cells in the pathogenesis of COPD in Z-alpha-1 antitrypsin deficiency. Respir. Res. 2014; 15 (1): 112.

7. Greene C.M., Hassan T., Molloy K. et al. The role of proteases, endoplasmic reticulum stress and SERPINA1 heterozygosity in lung disease and $\alpha_{1}$-antitrypsin deficiency. Exp. Rev. Respir. Med. 2011; 5 (3): 395-411.

8. Пузырев В.П., Огородова Л.М. Альфа1-антитрипсиновая недостаточность. В кн.: Чучалин А.Г., ред. Генетика бронхолегочных заболеваний. М.: Атмосфера; 2010: 38-50.

9. Alam S., Li Z., Atkinson C. et al. Z. Alpha1-antitrypsin confers a proinflammatory phenotype that contributes to chronic obstructive pulmonary disease. Am. J. Respir. Crit. Care Med. 2014; 189 (8): 909-931.

10. Видаль Р., Бланко И., Касас Ф. и др. Рекомендации по диагностике и ведению больных с дефицитом $\alpha_{1}$-антитрипсина Испанского общества пульмонологии и торакальной хирургии (SEPAR). Пульмонология. 2008; 1: 14-28.

11. Ferrarotti I., Thun G.A., Zorzetto M. et al. Serum levels and genotype distribution of alpha1-antitrypsin in the general population. Thorax. 2012; 67 (8): 669-674.

12. Сатыкова С.Ж. Уровень $\alpha$-1-антитрипсина у этнических кыргизов с хронической обструктивной болезнью легких: Дисс. ... канд. мед. наук. Бишкек; 2011.

13. American Thoracic Society / European Respiratory Society Statement: Standards for the diagnosis and management of individuals with alpha-1 antitrypsin deficiency. Am. J. Respir. Crit. Care Med. 2003; 168: 818-900.

14. Campos M.A., Kueppers F., Stocks J.M. et al. Safety and pharmacokinetics of $120 \mathrm{mg} / \mathrm{kg}$ versus $60 \mathrm{mg} / \mathrm{kg}$ weekly intravenous infusions of alpha-1 proteinase inhibitor in alpha-1 antitrypsin deficiency: a multicenter, randomized, double-blind, crossover study (SPARK). COPD. 2013; 10 (6): 687-695.

15. Saferali A., Lee J., Sin D.D. et al. Longer telomere length in COPD patients with $\alpha_{1}$-antitrypsin deficiency independent of lung function. PLoS ONE. 2014; 9 (4): e95600.

Поступила 11.11.14 Удк 616.24-008.962-008.64

\section{References}

1. Aver'yanov A.V., Polivanova A.E. Alfa1-antitripsin deficiency and chronic obstructive pulmonary disease. Pul'monologiya. 2007; 3: 103-109 (in Russian).
2. Strange C., Stoller J.K., Sandhaus R.A. et al. Results of a survey of patients with alpha1-antitrypsin deficiency. Respiration. 2006; 73: 185-190.

3. Brodskaya O.N. Inherited alfa1-antitripsin deficiency. Atmosfera. Pul'monologiya i allergologiya 2008; 4: 58-59 (in Russian).

4. Dawwas M.F., Davies S.E., Griffiths W.J. et al. Prevalence and risk factors for liver involvement in individuals with PiZZ-related lung disease. Am. J. Respir. Crit. Care Med. 2013; 187 (5): 502-508.

5. Olisova O.Yu., Grabovskaya O.V., Teplyuk N.P. et al. Panniculitis caused by alfa1-antitripsin deficiency. Rossiyskiy zhurnal kozhnykh $i$ venericheskikh bolezney. 2014; 3: 32-35 (in Russian).

6. Pini L., Tiberio L., Venkatestan N. et al. The role of bronchial epithelial cells in the pathogenesis of COPD in Z-alpha-1 antitrypsin deficiency. Respir. Res. 2014; 15 (1): 112.

7. Greene C.M., Hassan T., Molloy K. et al. The role of proteases, endoplasmic reticulum stress and SERPINA1 heterozygosity in lung disease and $\alpha_{1}$-antitrypsin deficiency. Exp. Rev. Respir. Med. 2011; 5 (3): 395-411.

8. Puzyrev V.P., Ogorodova L.M. Alfa1-antitripsin deficiency. In.: Chuchalin A.G., ed. Genetics of respiratory diseases. Moscow: Atmosfera; 2010: 38-50 (in Russian).

9. Alam S., Li Z., Atkinson C. et al. Z. Alpha1-antitrypsin confers a proinflammatory phenotype that contributes to chronic obstructive pulmonary disease. Am. J. Respir. Crit. Care Med. 2014; 189 (8): 909-931.

10. Vidal' R., Blanko I., Kasas F. et al. Clinical guidelines of Spanish Society of Pulmonology and Thoracic Surgery on diagnosis and management of patients with $\alpha_{1}$-antitripsin deficiency. Pul'monologiya. 2008; 1: 14-28 (in Russian).

11. Ferrarotti I., Thun G.A., Zorzetto M. et al. Serum levels and genotype distribution of alpha1-antitrypsin in the general population. Thorax. 2012; 67 (8): 669-674.

12. Satykova S.Zh. Alfa1-antitripsin level in ethnic Kyrgyz with chronic obstructive pulmonary disease: Dis. Bishkek; 2011 (in Russian).

13. American Thoracic Society / European Respiratory Society Statement: Standards for the diagnosis and management of individuals with alpha-1 antitrypsin deficiency. Am. $J$. Respir. Crit. Care Med. 2003; 168: 818-900.

14. Campos M.A., Kueppers F., Stocks J.M. et al. Safety and pharmacokinetics of $120 \mathrm{mg} / \mathrm{kg}$ versus $60 \mathrm{mg} / \mathrm{kg}$ weekly intravenous infusions of alpha-1 proteinase inhibitor in alpha-1 antitrypsin deficiency: a multicenter, randomized, double-blind, crossover study (SPARK). COPD. 2013; 10 (6): 687-695.

15. Saferali A., Lee J., Sin D.D. et al. Longer telomere length in COPD patients with $\alpha_{1}$-antitrypsin deficiency independent of lung function. PLoS ONE. 2014; 9 (4): e95600.

Received November 11, 2014 UDC 616.24-008.962-008.64

\section{Информация об авторе}

Соловьева Ольга Георгиевна - д. м. н., профессор кафедры гистологии с эмбриологией ГБОУ ВПО "Тюменская государственная медицинская академия" Минздрава России, врач-пульмонолог Консультативно-диагностической поликлиники им. Е.М.Нигинского; тел.: (345) 290-62-62, (345) 220-30-93; e-mail: solog.fedor@mail.ru

\section{Author information}

Solov'eva Ol'ga Georgievna, MD, Professor at Department of Histology and Embryology, E.M.Niginskiy Tyumen' State Medical Academy, Healthcare Ministry of Russia; pulmonologist at E.M.Niginskiy Reference Outpatient Clinic; tel.: (345) 290-62-62, (345) 220-30-93; e-mail: solog.fedor@mail.ru 